\title{
AFTER SCHOOL CARE: ALTERNATIF LAYANAN PENDIDIKAN DAN PENGASUHAN BAGI ANAK USIA 6-8 TAHUN
}

\author{
Rudiyanto $^{1}$, Euis Kurniati ${ }^{2}$, Andhin Dyas Fitriani ${ }^{3}$, Ira Rengganis ${ }^{4}$, Mirawati ${ }^{5}$ \\ ${ }^{1-4}$ Universitas Pendidikan Indonesia \\ ${ }^{5}$ Universitas Muhammadiyah Tasikmalaya \\ Email : euiskurniati@upi.edu
}

\begin{abstract}
ABSTRAK
Artikel ini merupakan kajian literatur terkait layanan pendidikan dan pengasuhan bagi anak usia 6-8 tahun pada kelas awal sekolah dasar. Pengasuhan pada anak memiliki kontribusi yang sangat besar terhadap berbagai perkembangan anak. Kebutuhan pengasuhan untuk anak usia sekolah, termasuk pada rentang usia 6-8 tahun sangatlah besar. Anak usia 6-8 tahun merupakan usia transisi dari jenjang pendidikan anak usia dini pada jenjang sekolah dasar. Salah satu program yang dapat memfasilitasi layanan pendidikan dan pengasuhan bagi anak adalah Program After School Care. Program ini merupakan salah satu upaya yang dilakukan untuk memenuhi kebutuhan dan memberikan layanan pendidikan serta pengasuhan bagi anak setelah pulang sekolah. Program ini bukan hanya dapat diakses oleh anak pada jenjang sekolah dasar, namun juga jenjang sekolah menengah pertama dan menengah atas, dengan layanan dukungan akademik, keminatan anak, pendampingan dan pemenuhan kebutuhan gizi Artikel ini diharapkan dapat memberikan wawasan terkait gambaran layanan pendidikan dan pengasuhan bagi anak usia 6-8 tahun dalam program after school care.
\end{abstract}

Kata Kunci: Pengasuhan, Pendidikan, After School Care

\begin{abstract}
This article is a literature review of education and care services for children aged 6-8 years in the early grades of elementary school. Care for children has a very large contribution to various children's development. Care needs for school-age children, including those in the 6-8 year age range, are very large. Children aged 6-8 years are a transition age from early childhood education at the elementary school level. One program that can facilitate education and care for children is the After School Care Program. This program is one of the efforts made to meet the needs and provide education and care services for children after school. This program is not only accessible for children at the elementary school level, but also for junior and senior high school levels, with academic support services, children's interest, assistance and fulfillment of nutritional needs. This article is expected to provide insight into the description of education and care services for children. 6-8 years of age in an after school care program.
\end{abstract}

Keywords: Parenting, Education, After School Care

PENDAHULUAN

Pengasuhan pada anak

merupakan hal yang sangat penting dan memiliki kontribusi yang sangat besar terhadap setiap aspek perkembangan anak. Selain itu, pengasuhan juga sangat 
RUDIYANTO, EUIS KURNIATI, ANDHIN DYAS FITRIANI, IRA RENGGANIS, MIRAWATI. AFTER SCHOOL CARE: ALTERNATIF LAYANAN PENDIDIKAN DAN PENGASUHAN BAGI ANAK USIA 6-8 TAHUN. Early Childhood Vol. 2 No. 2a, November 2018

berpengaruh terhadap perilaku, kepribadian serta keseimbangan emosi anak (Damayanti, 2011). Pengasuhan pada anak pertama kali dimulai dalam lingkungan keluarga dan kemudian ditunjang oleh lembaga pendidikan (Rudiyanto, 2010; Yusuf, 2012; Suyadi \& Ulfah, 2013). Hal tersebut menyiratkan bahwa orang tua dan pendidik memiliki peranan yang penting dalam memberikan pengasuhan yang baik pada anak. Berk (2007) menyatakan bahwa peran orang tua dan pendidik dalam melakukan pengasuhan adalah untuk membantu anak untuk memahami potensi yang dimilikinya dan pengasuhan tersebut dilakukan dengan membuat keputusan untuk lebih responsif, konsisten dan menjalin interaksi yang baik dengan anak. Dengan kata lain, dapat disimpulkan bahwa pengasuhan pada anak memiliki kontribusi yang sangat besar terhadap berbagai perkembangan anak.

Seperti yang telah diuraikan sebelumnya, layanan pengasuhan juga dapat ditunjang melalui lembaga pendidikan, salah satunya melalui program Taman Penitipan Anak (TPA). TPA merupakan salah satu bentuk satuan PAUD jalur pendidikan nonformal yang menyelenggarakan program pendidikan bagi anak sejak lahir sampai dengan usia 6 (enam) tahun dengan prioritas sejak lahir sampai usia 4 tahun (Depdikbud, 2015). Jika didasarkan pada pengertian tersebut, tersirat bahwa lembaga TPA hanya terbatas pada layanan pengasuhan anak hingga rentang usia 6 tahun atau dengan kata lain anak yang memiliki usia di atas 6 tahun tidak memiliki kesempatan untuk memperoleh layanan pengasuhan dalam TPA tersebut. Hal tersebut sangat disayangkan, karena justru beberapa kondisi di lapangan menunjukkan kebutuhan yang besar terhadap layanan pengasuhan untuk anak sekolah dasar kelas awal (usia 6-8 tahun). Salah satu penelitian menunjukkan betapa besarnya kebutuhan pengasuhan bagi anak sekolah, pernyataannya antara lain sebagai berikut:

"School-aged children need high quality, developmentally appropriate and educationally valued care, with a safe environment for learning and development". (Demircan \& Demir, 2014, hlm. 169).

Kebutuhan pengasuhan bagi anak usia sekolah seperti yang telah diuraikan sebelumnya semakin 
meningkat dari tahun ke tahun, salah satunya karena faktor pekerjaan orang tua. Orang tua memiliki kekhawatiran terhadap pemenuhan kebutuhan anak ketika pulang sekolah, terutama karena mereka memiliki keterbatasan waktu untuk memenuhi kebutuhan anak tersebut, seperti yang diungkapkan oleh Barnett, Gareis, Sabattini \& Carter (2010, hlm. 606):

"Most employed parents, many in dual-earner couples, are at work when their children get out of school, generating parental concerns about children's welfare After School".

Berdasarkan uraian di atas, dapat terlihat bahwa kebutuhan pengasuhan untuk anak usia sekolah, termasuk pada rentang usia 6-8 tahun sangatlah besar. Anak usia 6-8 tahun merupakan usia transisi dari jenjang pendidikan anak usia dini pada jenjang sekolah dasar. Pada rentang usia tersebut, anak mengalami peralihan kondisi dan situasi belajar yang lebih menekankan kemandirian anak dan tugas perkembangan yang lebih kompleks (Santrock, 2013). Namun, sekalipun anak SD kelas awal dituntut untuk jauh lebih mandiri, pada dasarnya anak pada usia tersebut masih belum mampu memenuhi segala kebutuhannya secara mandiri (Polatnick, 2002). Anak masih memerlukan bantuan dan layanan pengasuhan yang tepat, terutama terkait dengan pemenuhan kebutuhan gizinya. Bahkan, jika mengacu pada pengertian anak usia dini dalam ranah internasional, anak usia 6-8 tahun masih termasuk ke dalam jenjang anak usia dini. Hal tersebut sesuai dengan pernyataan Bredecamp \& Cople (1997) yang berarti bahwa pendidikan anak usia dini mencakup berbagai program yang melayani anak dari lahir sampai usia 8 tahun yang dirancang untuk meningkatkan perkembangan intelektual, sosial emosional dan bahasa dan fisik anak.

Jika mengacu pada pernyataan di atas, tersirat bahwa anak pada jenjang sekolah dasar kelas awal masih termasuk pada kategori anak usia dini. Maka dari itu, hendaknya anak memiliki kesempatan untuk memperoleh layanan pengasuhan pada lembaga pendidikan tertentu. Salah satu program yang dapat memfasilitasi hal tersebut adalah After School program $(A S P)$. Program ini merupakan salah satu upaya yang dilakukan untuk memenuhi kebutuhan dan memberikan 
RUDIYANTO, EUIS KURNIATI, ANDHIN DYAS FITRIANI, IRA RENGGANIS, MIRAWATI. AFTER SCHOOL CARE: ALTERNATIF LAYANAN PENDIDIKAN DAN PENGASUHAN BAGI ANAK USIA 6-8 TAHUN. Early Childhood Vol. 2 No. $2 a$, November 2018

layanan pendidikan serta pengasuhan bagi anak setelah pulang sekolah. Program ini bukan hanya dapat diakses oleh anak pada jenjang sekolah dasar, namun juga jenjang sekolah menengah pertama dan menengah atas, dengan layanan dukungan akademik, keminatan anak, pendampingan dan pemenuhan kebutuhan gizi (Yohalem, Pittman, and Edwards, 2010).

Program After School ini banyak memberikan kontribusi terhadap perkembangan anak, salah satunya yang tercantum dalam hasil penelitian Durlak, Weissberg \& Pachan (2010) yang menyatakan bahwa ASP dapat berkontribusi terhadap perkembangan kepribadian dan sosial anak dan remaja. Durlak \& Weissberg (2007, Hlm. 7) menekankan bahwa:

"Youth who participate in After School programs improve significantly in three major areas: feelings and attitudes, indicators of behavioral adjustment, and school performance".

Program After School juga berkontribusi terhadap stimulasi aktivitas fisik dan peningkatan hasil belajar anak (Cheung, 2012; Urbel, 2015). Selain itu, manfaat lain dari After School adalah adanya pendampingan anak dalam pekerjaan rumah yang dapat membantu meminimalkan kesulitan siswa dalam mempelajari suatu konsep sehingga terhindar dari kegagalan belajar (Cosden, Morrison, Albanese \& Macias, 2001).

Uraian di atas menyiratkan bahwa program After School ini dapat dijadikan sebagai alternatif layanan pendidikan dan pengasuhan bagi anak sekolah dasar.

\section{METODE PENELITIAN}

Metode yang digunakan dalam penulisan artikel ini adalah literature review atau kajian berbagai sumber teori terkait dengan pendidikan dan pengasuhan bagi anak usia 6-8 tahun. Adapun proses penulisan tinjauan literatur dalam artikel ini mengacu pada pendapat Galvan \& Melisa (2017) yang meliputi tahapan sebagai berikut:

1. Perencanaan. Penulis mendefinisikan topik dan memilih literatur untuk dikaji secara khusus. Kedua langkah ini saling berkaitan satu sama lain karena topik yang ditentukan akan menentukan literatur tertentu yang akan diidentifikasi, begitu pun hasil pencarian literatur akan memandu dalam menentukan topik. Pada tahapan ini penulis melakukan pemilihan artikel/jurnal atau literatur lain yang 
RUDIYANTO, EUIS KURNIATI, ANDHIN DYAS FITRIANI, IRA RENGGANIS, MIRAWATI. AFTER SCHOOL CARE: ALTERNATIF LAYANAN PENDIDIKAN DAN PENGASUHAN BAGI ANAK USIA 6-8 TAHUN. Early Childhood Vol. 2 No. $2 a$, November 2018

relevan dengan mengunjungi perpustakaan, internet searching atau pencarian bahan pustaka untuk mencari teori yang relevan dengan topik yang dipilih yaitu terkait pendidikan dan pengasuhan bagi anak usia 6-8 tahun.

2. Pengorganisasian. Penulis melakukan analisis, mensintesis, dan mengevaluasi rujukan-rujukan literatur yang akan yang dikaji. Setelah menemukan koleksi yang memadai artikel tentang topik terkait hak bermain bagi anak usia dini, penulis melanjutkan pada tahap membaca dan menganalisis koleksi literature, kemudian menempatkan catatan hasil analisis menjadi kerangka organisasi yang baru dan melakukan evaluasi terhadap isi catatan tersebut.

3. Drafting. Penulis melakukan penyusunan draft pertama hasil review terkait pendidikan dan pengasuhan bagi anak usia 6-8 tahun dalam bebagai literature.

4. Editing. Penulis pada tahap ini melakukan pemeriksaan terhadap kelengkapan, kohesi, dan kebenaran draft pertama yang telah disusun

5. Redrafting. Pada tahapan ini penulis melakukan penyusunan ulang, penulis menulis ulang draft (disusun kembali) sesuai dengan hasil editing.
Program After School merupakan salah satu upaya yang dilakukan untuk memenuhi kebutuhan dan memberikan layanan pendidikan serta pengasuhan bagi anak setelah pulang sekolah. Program ini bukan hanya dapat diakses oleh anak pada jenjang sekolah dasar, namun juga jenjang sekolah menengah pertama dan menengah atas, dengan layanan dukungan akademik, keminatan anak, pendampingan dan pemenuhan kebutuhan gizi. Hal tersebut sesuai dengan pernyataan Yohalem, dkk., (2010, hlm. 4):

"Afterschool programs serve children and youth of all ages, and encompass a broad range of focus areas including academic support, mentoring, youth development, arts, and sports and recreation".

Pernyataan di atas dapat diartikan bahwa program After School adalah salah satu layanan pendidikan dan pengasuhan bagi anak dan remaja yang dilaksanakan ketika pulang sekolah dengan pemberian dukungan akademik, pendampingan, pengembangan pribadi, kesenian, olah raga dan rekreasi.

\section{KAJIAN LITERATUR}

\section{Definisi Program After School}


RUDIYANTO, EUIS KURNIATI, ANDHIN DYAS FITRIANI, IRA RENGGANIS, MIRAWATI. AFTER SCHOOL CARE: ALTERNATIF LAYANAN PENDIDIKAN DAN PENGASUHAN BAGI ANAK USIA 6-8 TAHUN. Early Childhood Vol. 2 No. 2a, November 2018

\section{Manfaat Program After School}

Program After School memiliki banyak manfaat terhadap berbagai aspek perkembangan anak, antara lain sebagai berikut:

a Pemenuhan Kebutuhan Gizi Anak

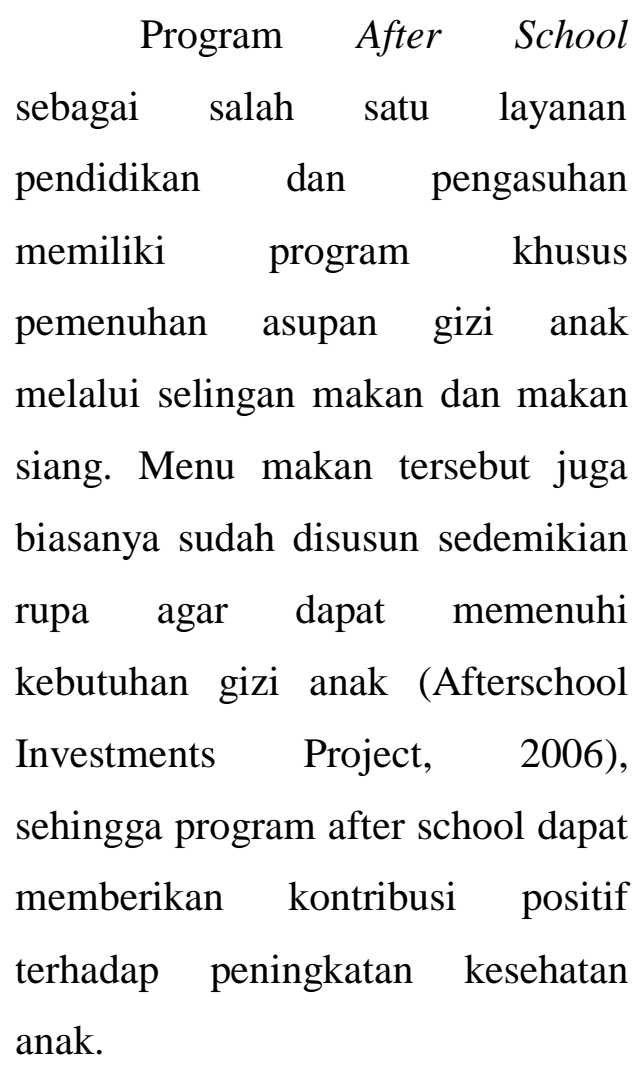

\section{b Stimulasi Aspek Fisik Anak}

Program After School yang memiliki physical activity (PA) berkontribusi terhadap stimulasi aktivitas fisik dan peningkatan hasil belajar anak. Penelitian yang dilakukan oleh Cheung (2012, hlm. 183) menunjukan bahwa:

"......that an after-school
programme is an ideal
channel for promoting
children's PA because it is
in a structured
environment."

Penelitian

tersebut menunjukkan bahwa program after school merupakan salah satu program ideal yang dapat menstimulasi perkembangan fisik anak. Selain itu menurut Hager (2006) \& Mota dkk., (2003) after school merupakan periode penting dimana anak mengalami puncak kegiatan dalam kesehariannya. Anak juga lebih banyak terlibat dalam aktivitas fisik sepulang sekolah (Sirard dkk., 2005; Prochaska dkk., 2002). Senada dengan beberapa penelitian di atas, Mahoney, J., Lord, H., \& Carryl (2005) juga menyatakan bahwa program After School memiliki peran yang penting dalam meningkatkan aktivitas fisik anak dan kebiasaan diet yang baik untuk kesehatan anak, sehingga dapat membantu menurunkan tingkat obesitas anak. 


\section{c Perkembangan Kepribadian} dan Sosial Anak

Durlak, Weissberg \& Pachan (2010) menyatakan bahwa ASP dapat berkontribusi terhadap perkembangan kepribadian dan sosial anak dan remaja. Durlak \& Weissberg (2007, Hlm. 7) menekankan bahwa:

"Youth who participate in After School programs improve significantly in three major areas: feelings and attitudes, indicators of behavioral adjustment, and school performance".

Pernyataan di atas berarti bahwa program After School dapat meningkatkan kemampuan anak dalam mengolah perasaan, sikap dan perilaku anak serta hasil belajar di sekolah. Dalam hal ini dapat disimpulkan bahwa program after school dapat membantu stimulasi terhadap pengembangan kepribadian dan sosial anak.

\section{d Peningkatan Hasil Belajar Anak}

$$
\text { Manfaat lain dari After }
$$
School adalah adanya pendampingan anak dalam pekerjaan rumah yang dapat membantu meminimalkan kesulitan siswa dalam mempelajari suatu konsep sehingga terhindar dari kegagalan belajar. Hal tersebut sesuai dengan hasil penelitian Cosden, dkk., (2001, hlm. 211) yang menunjukkan bahwa:

"The data suggest that afterschool homework-assistance programs can serve a protective function for children at-risk for school failure, particularly those who do not have other structured after-school activities".

Berdasarkan uraian di atas dapat dismpulkan bahwa program After School banyak memberikan manfaat bagi perkembangan anak dan dapat dijadikan sebagai alternatif pemenuhan kebutuah anak, maka dari itu pengembangan program ini sangat diperlukan agar mampu menjadi program berkualitas yang dapat berkontribusi terhadap pembentukan generasi penerus Indonesia yang unggul.

\section{Bentuk Program After School Care}

Program after school yang akan dikembangkan dalam penelitian ini mengacu pada Afterschool Investments 
RUDIYANTO, EUIS KURNIATI, ANDHIN DYAS FITRIANI, IRA RENGGANIS, MIRAWATI. AFTER SCHOOL CARE: ALTERNATIF LAYANAN PENDIDIKAN DAN PENGASUHAN BAGI ANAK USIA 6-8 TAHUN. Early Childhood Vol. 2 No. 2a, November 2018

Project (2006) dengan beberapa penyesuaian. Layanan After School Care antara lain meliputi layanan kesehatan dan gizi, pendampingan tugas mata pelajaran, kegiatan seni dan aktivitas olah raga, serta program anak peduli lingkungan (APEL) yang meliputi kegiatan berkebun serta daur ulang sampah.

\section{SIMPULAN}

After School program (ASP) merupakan salah satu upaya yang dilakukan untuk memenuhi kebutuhan dan memberikan layanan pendidikan serta pengasuhan bagi anak sekolah dasar kelas awal pada rentang usia 6-8 tahun. Program ini dapat diakses oleh anak pada jenjang sekolah dasar, dengan layanan dukungan akademik, keminatan anak, pendampingan dan pemenuhan kebutuhan gizi.

\section{DAFTAR PUSTAKA}

After School Investments Project. (2006). The Afterschool Investments Project Resource List. US: ASIP \& Department of Health and Human Services.

Barnett, R. C., Gareis, K.C., Sabattini. L., \& Carter, N. M. (2010). Parental concerns about after-school time: antecedents and correlates among dual-earner parents. Journal of Family Issues, 31 (5), p. 606 -625. DOI: 10.1177/0192513X0935301 9.

Berk, Laura. (2007). Development through the lifespan. United Stated of America: Allyn and Bacon.

Bredekamp, S. (1997). Developmentally Appropriate Practice in Early Childhood Programs. Washington: NAEYC

Cheung, P. P. (2012). Association of after-school physical activity levels and organized physical activity participation in Hong Kong children. European Physical Education Review, 18(2) 182-190. DOI: $10.1177 / 1356336 \mathrm{X} 1244002$ 1.

Cosden, M., Morrison, G., Albanese, A.L., \& Macias, S. (2001). When homework is not home work: after-school programs for homework assistance. Educational Psychologist, 36 (3), p. 211221. 
Damayanti, P A (2011). Dinamika perilaku "nakal" anak berambut gimbal di dataran tinggi dieng. Jurnal Psikologi Islam (JPI) Lembaga Penelitian Pengembangan Psikologi dan Keislaman (LP3K), 8 (2), hlm. 165-190.

Demircan, Ö. H \& Demir. A. (2014). Children's sense of loneliness and social dissatisfaction, after-school care. Psychological Reports: Mental \& Physical Health, 114 (1), p. 169-175. DOI

10.2466/10.17.PR0.114k10 w4.

Depdikbud. (2015). Petunjuk Teknis Penyelenggaraan Taman Penitipan Anak. Jakarta: Direktorat Jendral PAUD, Departemen Pendidikan dan Kebudayaan.

Durlak, J. A, \& Weissberg, R. P. (2007). The Impact of AfterSchool Programs That Promote Personal and Social Skills. Chicago: Collaborative for Academic, Social, and Emotional Learning (CASEL),

Durlak, J. A, Weissberg, R.P \& Pachan, M. (2010). A meta-analysis of after-school programs that seek to promote personal and social skills in children and adolescents. Am J Community Psychol, 45 (1), p. 294-309. DOI 10.1007/s10464-010-9300-

6.

Galvan. J.L \& Mellisa. G. (2017). Writing Literature Reviews, A Guide for Students of the Social and Behavioral Sciences Seventh Edition. New York: Routledge.

Garey. A. I. (2002). Social domains and concepts of care: protection, instruction, and containment in after-school programs. Journal Of Family Issues, 23 (6), p. 768-788.

Hager RL (2006) Television viewing and physical activity in children. The Journal of Adolescent Health 39: 656661.

Heppner, Wampold \& Kivlighan. (2008). Reserach Design in Counseling, Third Edition. USA: Thomson Brooks/Cole.

Mahoney, J., Lord, H., \& Carryl (2005). An ecological analysis of after-school program participation and the development of academic 
RUDIYANTO, EUIS KURNIATI, ANDHIN DYAS FITRIANI, IRA RENGGANIS, MIRAWATI. AFTER SCHOOL CARE: ALTERNATIF LAYANAN PENDIDIKAN DAN PENGASUHAN BAGI ANAK USIA 6-8 TAHUN. Early Childhood Vol. 2 No. 2a, November 2018

$$
\begin{aligned}
& \text { performance and } \\
& \text { motivational attributes for } \\
& \text { disadvantaged children. } \\
& \text { Child Development, } 76 \text { (4), } \\
& \text { p. 811-825. }
\end{aligned}
$$

Mirawati. (2016). The Little Gardener:

Science Learning for Children. Social Science, Education and Humanities Research (ASSEHR), volume 58. p. 307-311.

Mota JP, Santos S, Guerra JC and Ribeiro JD (2003) Patterns of daily physical activity during school days in children and adolescents. American Journal of Human Biology 15: 547-553.

Polatnick, M.R. (2002). Too old for child care? Too young for self-care? Negotiating afterschool arrangements for middle school. Journal of Family Issues, 23 (6), p. 728-747.

Prochaska JJ, Sallis JF, Griffith B and Douglas J (2002) Physical activity levels of Barbadian youth and comparison to a US sample. International Journal of Behavioral Medicine 9: 360-372.

Rudiyanto. (2010). Pemberdayaan Masyarakat dalam
Penyelenggaraan PAUD.

Bandung: Program

Pendidikan Guru

Pendidikan Anak Usia Dini UPI.

Santrock, J.W. (2013). Life-Span Development $\left(14^{\text {th }}\right.$ Ed.). New York: McGraw-Hill.

Sirard JR, Riner WF, McIver KL and Pate RR (2005) Physical activity and active commuting to elementary school. Medicine and Science in Sports and Exercise 37: 2062-2069.

Suyadi \& Ulfah. M. (2013). Konsep Dasar PAUD. Bandung: PT Remaja Rosdakarya.

Urbel. J-L. (2015). What works after school? The relationship between after-school program quality, program attendance, and academic outcomes. Youth \& Society, 47(5), p. 684 -706. DOI: $10.1177 / 0044118 X 1351347$ 8.

Weitzman, B.C., Mijanovich, T., Silver, D., \& Brazill, C. (2008). If you build it, will they come? Estimating unmet demand for afterschool programs in america's distressed cities. 
RUDIYANTO, EUIS KURNIATI, ANDHIN DYAS FITRIANI, IRA RENGGANIS, MIRAWATI. AFTER SCHOOL CARE: ALTERNATIF LAYANAN PENDIDIKAN DAN PENGASUHAN BAGI ANAK USIA 6-8 TAHUN. Early Childhood Vol. 2 No. 2a, November 2018

Youth \& Society, 40 (1), p.

3-34. DOI

$10.1177 / 0044118 X 0831426$

2.

Yohalem, N., Pittman, K., \& Edwards, L.S. (2010). Strengthening the Youth

Development/After-School

Workforce: Lessons

Learned and Implications

for Funders.

Houston, TX: Cornerstones

for Kids.

Yusuf. S. (2012). Psikologi Perkembangan Anak dan

Remaja. Bandung: PT

Remaja Rosdakarya. 